\title{
Why do adolescents eat what they eat? Personal and social environmental predictors of fruit, snack and breakfast consumption among 12-14-year-old Dutch students
}

\author{
MK Martens ${ }^{1, *}$, P van Assema ${ }^{1}$ and J Brug ${ }^{1,2}$ \\ 'Department of Health Education and Promotion, Maastricht University, PO Box 616, 6200 MD Maastricht, \\ The Netherlands: ${ }^{2}$ Department of Public Health, Erasmus Medical Centre, Rotterdam, The Netherlands
}

Submitted 10 October 2004: Accepted 30 June 2005

\begin{abstract}
Objective: The aim of the study was to investigate the relative importance of personal and social environmental predictors of the consumption of fruit, high-fat snacks and breakfast.

Design: A school-based cross-sectional survey. Data were collected through written questionnaires.

Setting: Students from eight schools in the southern part of The Netherlands.

Subjects: Six hundred and one students from preparatory secondary vocational education schools.

Results: About a quarter of the variation in actual behaviours and intentions to change the behaviours could be explained. Stepwise multiple regression analysis revealed that, for all three behaviours, higher intention to change was especially associated with a more positive attitude and subjective norm, and higher intentions to increase fruit intake with more positive self-efficacy expectations. With regard to actual consumption, a more positive attitude towards eating fruit was the only significant correlate of a higher consumption of fruit. A more positive attitude towards eating high-fat snacks, perceived lower intake of the mother, and higher food availability and accessibility were associated with consumption of high-fat snacks, and a more positive attitude to breakfast more frequently was associated with more frequent breakfast consumption.

Conclusion: The results indicate that adolescents' attitudes are the most important determinants of different health-related eating behaviours and intentions to change. Interventions promoting a healthy diet for adolescents should include creative strategies to achieve positive associations with healthy dietary changes.
\end{abstract}

Keywords
Adolescents
Nutrition
Behavioural determinants
Unhealthy dietary habits, such as low fruit consumption, frequent consumption of high-fat snacks and skipping breakfast, are common among adolescents in The Netherlands as well as other Western countries ${ }^{1-5}$. These behaviours have been found to be associated with increased risk of overweight and obesity, difficulties concentrating in school and, in the longer run, a higher risk for chronic diseases such as diabetes, cardiovascular diseases and certain types of cancer ${ }^{6-9}$. The number of adolescents who are overweight or obese is a rapidly growing problem in The Netherlands, as in many other countries $^{10-12}$. Improving the nutritional habits of adolescents is therefore important. Moreover, healthy eating at an early age may be an important determinant for dietary choices later in life $\mathrm{e}^{13-15}$. In particular, when minors transfer from elementary school to secondary school their eating habits change and become less favourable ${ }^{16}$. Intervening at that age may therefore prevent unhealthy eating behaviour becoming habitual and thus difficult to change. Further, adolescents from groups with lower socio-economic position (SEP) have less favourable diets than their peers from higher SEP groups $^{17,18}$. Interventions promoting a healthy diet should therefore be suitable especially for lower SEP groups.

In order to develop planned interventions to promote healthy eating, it is necessary to gain insight into the potential determinants of dietary practices ${ }^{19}$. The objective of the present study was to investigate the relative importance of personal and social environmental predictors of specific dietary behaviours, with the aim of identifying programme objectives for interventions aimed at encouraging 12-14-year-old low-level high school students to increase their consumption of fruit, decrease their consumption of high-fat snacks, and increase breakfast frequency and quality. 
A model that has been used before for the assessment of determinants of dietary behaviour is the ASE (attitudesocial influence-efficacy) model ${ }^{20}$. In the ASE model, behaviour is considered to be primarily a result of behavioural intention. Three main psychosocial factors have been identified that predict intention, namely attitude, social influence and self-efficacy. A person's attitude towards a specific behaviour is the result of the expected effects of performing such behaviour. Social influence is a result of subjective norms that are relevant to this behaviour, perceived support from others to express or refrain from the behaviour, and whether important others perform or refrain from such behaviour (descriptive norm). Self-efficacy expectations are the result of a person's beliefs about his or her abilities to perform the desired behaviour. Apart from its influence on behavioural intention, self-efficacy is also expected to influence behaviour directly. External variables, such as sociodemographic factors, are expected to influence behaviour through behavioural determinants and intention. Behaviour, or attempted behaviour, leads to feedback that may influence the determinants ${ }^{20}$. A number of additional determinants have been proposed. For children, their family environment may be of special importance. In particular family food rules about food - the restrictions or obligations for children to eat certain foods - have been found to influence the dietary behaviour of adolescents ${ }^{21}$. Further, earlier studies have found that availability and accessibility of foods are important predictors of children's dietary intake, which means that items of fruit or breakfast need to be available and accessible for children to be able to eat them ${ }^{17,22}$.

In the present study, the above-mentioned potential predictors of consumption of fruit, high-fat snacks and breakfast were studied in a school-based survey.

\section{Method}

\section{Respondents and procedure}

In The Netherlands, secondary education is divided into different levels: university preparatory education, senior general secondary education and preparatory secondary vocational education. Children with a lower SEP background are over-represented at preparatory secondary vocational education. A random sample of eight schools was drawn from a list of addresses of preparatory secondary vocational education schools in the southern part of The Netherlands. All schools agreed to participate after they had received written and oral information about the study. In these schools, teachers selected one or more classes with 12-14-year-old students. These students were asked to complete a written self-administered questionnaire during school hours. Completion took about $20 \mathrm{~min}$. All students who were present during data collection hours agreed to participate.

\section{Questionnaire}

Separate questionnaires were developed for each of the three types of risk behaviour: consumption of fruit, intake of high-fat snacks and breakfast habits. Administration of more than one of the questionnaires among the same students was not possible because of time restraints. Classes were therefore randomly assigned for all children in a class to receive one of the three questionnaires.

\section{Demographic factors}

In the first part of the questionnaire, some demographic factors were measured, such as gender and age. In addition, students were asked whether they lived with both parents or in a different home situation. Lastly, children were asked about the native country of their parents.

\section{Dietary habits}

Consumption of fruit was assessed using the fruit questions from a validated fruit and vegetable food-frequency questionnaire $^{23}$. In two separate items, students indicated how many days a week they consumed fruit and fruit juice. They also indicated the number of pieces of fruit or glasses of fruit juice they consumed on such days. Students were also asked to write down which fruit and fruit juices they consumed most often. Frequency and quantity were multiplied to obtain estimates of mean consumption of fruit in pieces per day and mean consumption of juice in glasses per day. Consumption of high-fat snacks was assessed using items from a larger validated foodfrequency questionnaire to assess fat intake ${ }^{24}$. Four items questioned how many days a week the following snacks were consumed: fried snacks, nuts and potato chips, pastries and candy bars, and cookies. On the basis of these four items, a single score was calculated for the mean number of days per week on which these high-fat snacks were eaten. One item asking students how many days a week they ate breakfast was used to assess breakfast habits. In addition, students were asked, using different answer categories, where they usually consume fruit and/or fruit juice, high-fat snacks and breakfast (e.g. in school, at home) and when they consume fruit and/or fruit juice and high-fat snacks (e.g. in the morning) most often.

\section{Personal and social environmental determinants}

Unless mentioned otherwise, 5-point scaled items were used (scale from -2 to +2 ). Intention was assessed with one item on plans to change the behaviour in the next 6 months. Attitude was assessed by means of 12 to 14 items (depending on the dietary behaviour) on the consequences of the behaviour (e.g. eating fruit is tasty; eating snacks is enjoyable; I can concentrate better if I have breakfast). The scores on these items were summed and divided by the number of items to obtain a single score for attitude (Cronbach's $\alpha$ between 0.62 and 0.76). Descriptive norm was assessed by two items that questioned perceived behaviour of the mother and father. The inter-item 
correlation of the two items was low and therefore no scale could be formed for descriptive norm. Four items about perceived norm of the mother, father, brother(s)/sister(s) and friends measured the subjective norm. The scores on these items were summed and divided by four to obtain a single score for subjective norm (Cronbach's $\alpha$ between 0.69 and 0.84). Two items assessed social support of the mother and father by asking how strongly the desired behaviour was supported by the mother or father. The items were summed and divided by two to obtain a single score for social support (inter-item correlation coefficients between 0.60 and 0.61). Self-efficacy was assessed with two items measuring how confident students were about showing the desired behaviour and how easy it was to show this behaviour. The inter-item correlations, however, were moderate (inter-item correlation between 0.34 and 0.54). Further, the answer to the question on how confident students were was extremely biased towards the positive answers (high confidence) for all three types of behaviour. This indicates that inclusion of this item did not result in substantial variance in self-efficacy for a large majority of the respondents. Therefore, only the item dealing with the easiness of showing the desired behaviour was included in the analyses as a measure for self-efficacy.

In the fruit and breakfast questionnaires, the presence of family food rules was measured with one item with two possible answers (i.e. yes, there are rules in some way; no attention is paid). In the snack questionnaire the presence of food rules was measured for three different snack categories (fried snacks, nuts and potato chips, and pastries, candy bars and cookies) separately. These three items were summed and divided by three to obtain one score for food rules (Cronbach's $\alpha=0.70$ ). Subsequently the score was transformed to a categorical scale similar to the food rules scores for fruit and breakfast. We assumed that the family food rules encouraged performance of the desired behaviours. In the fruit questionnaire, availability and accessibility of food were measured with seven items (is fruit/fruit juice available at home; is there enough variety of fruit at home; if you were to indicate at home that you like a certain fruit/fruit juice would your parents buy them; is fruit available in a fruit bowl; do you get fruit to take to school). Three-point scales were used to answer these items (usually yes; sometimes; usually no). The item scores were summed to form a single score for a food availability and accessibility index. Food availability and accessibility were measured in a similar way in the snack questionnaire, using seven items (if you were to indicate at home that you like certain fried snacks/nuts or potato chips/pastries, candy bars or cookies would your parents buy them; are fried snacks/nuts or potato chips/pastries, candy bars or cookies available at home; do you get snacks to take to school). The breakfast questionnaire measured food availability and accessibility in a similar way, using four items (if you were to indicate at home that you like certain breakfast items would your parents buy them; are breakfast items available at home; is the table set for breakfast; are you having breakfast at a table).

\section{Analyses}

Statistical analyses were performed using the SPSS program (version 9.01; SPSS Inc., Chicago, IL, USA). To identify potential predictors of the three types of behaviours in the study, two sets of stepwise regression analyses were conducted for each type of behaviour. First, the intention to adopt a particular type of behaviour was regressed in three steps on the hypothesised personal and social environmental predictors, being gender, age (step 1), attitude, descriptive norm of the mother, descriptive norm of the father, subjective norm, social support, self-efficacy (step 2), existence of food rules, and fruit availability and accessibility (step 3). Second, the consumption score was regressed on the same set of variables, in which intention was included as an additional independent variable in step 2. Normality of the dependent variables was found to be acceptable for performance of regression analyses.

\section{Results}

The results are presented for each behaviour separately. Since the results did not show any substantial differences between the different steps in the regression analysis, only the final regression models are discussed.

\section{Fruit}

Two hundred and four students, 52\% male, completed the fruit questionnaire. Ten per cent were 12 years old, 53\% were 13 years old and 37\% were 14 years old. Most students (75\%) lived with both parents. Most students had parents whose native country was The Netherlands: $82 \%$ of the mothers and $80 \%$ of the fathers.

Mean fruit intake was 1.1 (standard deviation (SD) 0.9) pieces of fruit per day. Favourite fruits were apples, bananas, pears and oranges. Seventy-six per cent of the students did not eat the 2 pieces of fruit daily that are recommended in The Netherlands. Mean fruit juice intake was 1.4 (SD 1.0) glasses per day. However, fake fruit beverages, such as soft drinks with fruit taste, lemonade and yoghurt drinks with a fruit taste, were often reported as the most frequently consumed fruit juices. Therefore, analyses for fruit were done on the basis of the consumption of fresh fruit only. Almost all students indicated that fruit was mostly eaten at home (94\%), instead of at school (1\%) or elsewhere (5\%). Also, most students indicated that they eat fruit at varying times (92\%). The remaining students (8\%) reported to eat fruit exclusively during one of the main meals.

Except for social support, mean scores on the personal and social environmental predictors of consuming fruits were positive (Table 1). In particular, the perceived behaviour of the mother and self-efficacy towards eating 
Table 1 Means (standard deviation) of selected potential personal predictors of fruit, snack and breakfast consumption (all measured on a scale from -2 to +2 )

\begin{tabular}{|c|c|c|c|}
\hline & Fruit consumption & $\begin{array}{l}\text { Limit consumption } \\
\text { of high-fat snacks }\end{array}$ & $\begin{array}{l}\text { Breakfast } \\
\text { consumption }\end{array}$ \\
\hline Attitude $^{*}$ & $0.35(0.54)$ & $0.01(0.45)$ & $0.65(0.78)$ \\
\hline Perceived behaviour of mother $†$ & $0.46(1.01)$ & $0.93(0.91)$ & $0.97(1.30)$ \\
\hline Perceived behaviour of fathert & $0.11(1.15)$ & $0.53(1.02)$ & $0.65(1.35)$ \\
\hline Subjective norm $\ddagger$ & $0.22(0.78)$ & $-0.20(0.87)$ & $0.33(0.77)$ \\
\hline Social support§ & $-0.48(1.12)$ & $-0.14(1.14)$ & $-0.32(1.23)$ \\
\hline Self efficacy & $1.29(0.81)$ & $0.72(1.10)$ & $0.93(1.02)$ \\
\hline Intention to change $\|^{* *}$ & $0.10(1.20)$ & $0.14(1.26)$ & $-0.30(1.30)$ \\
\hline
\end{tabular}

${ }^{*}$ A positive score on attitude indicates a positive attitude towards eating fruit, limiting consumption of high-fat snacks and having breakfast.

†A positive score on descriptive norm indicates that students perceived their mother/father as eating many fruits, few high-fat snacks and having breakfast frequently.

$\ddagger$ A positive score on subjective norm indicates that students thought that other people think they should eat fruit, limit their consumption of high-fat snacks and have breakfast.

$\S A$ positive score on social support indicates that the students perceived their environment as supportive towards eating fruits, limiting their consumption of high-fat snacks and having breakfast.

I A positive score on self-efficacy indicates that students found it easy to eat more fruit, limit their consumption of high-fat snacks and have breakfast regularly.

$\|$ A positive score on intention indicates that students intended to increase their fruit consumption, limit their consumption of high-fat snacks and have breakfast more frequently in the next 6 months.

${ }^{\star *}$ Only students who were not already eating a breakfast seven days a week were selected.

fruit were positive, indicating that the students perceived their mothers as greater fruit-eaters and that they found it easy to eat more fruit. Perceived social support towards the consumption of fruit was negative, indicating that students perceived their environment as not supportive for eating fruit. The average score on intention to eat more fruits was almost neutral. Twenty-seven per cent of the students reported that there are rules at home about eating fruits (data not shown). Fruits were perceived to be widely available and accessible at home (mean 10.9, SD 2.0).

Attitude, perceived behaviour of the mother, perceived behaviour of the father, subjective norm, social support and self-efficacy were significant correlates of intention to increase consumption of fruit (Table 2). Students who had a greater intention of increasing their fruit consumption had a more positive attitude towards eating fruit, perceived their mother and father to eat few fruits, thought that other people think they should eat fruits, perceived their environment to support them in eating fruits, and found it easy to eat more fruits than students who had less intention to increase fruit consumption. Attitude was the only significant correlate of fruit consumption (Table 3). Intention towards increasing fruit consumption and perceived behaviour of the mother were of borderline significance $(P=0.053$ and 0.052 , respectively). Students who ate more fruit had a more positive attitude towards eating fruit, perceived their mother as greater fruit-eaters, and had a more negative intention towards increasing their fruit consumption than students who ate less fruits.

\section{High-fat snacks}

One hundred and ninety-four students, $41 \%$ male, completed the snack questionnaire. Thirteen per cent were 12 years old, 42\% were 13 years old and 45\% were 14 years old. Most students (80\%) lived with both parents. Eighty per cent of the mothers and $77 \%$ of the fathers of the students were born in The Netherlands.

On average students ate the different categories of highfat snacks on 2.4 (SD 1.3) days a week. Most students (63\%) indicated to consume fried snacks and nuts/potato chips most often at home, compared with at school (2\%), elsewhere (14\%) or varying (21\%). Also, most students indicated that snacks were mainly eaten in the evening (67\%). Fewer students (33\%) indicated to mainly eat them during the afternoon. About half the students reported to eat pastries, candy bars or cookies most often at home (52\%), compared with at school (36\%) or elsewhere (12\%). Also, most students reported these snacks were most often eaten during the afternoon (87\%). Fewer students reported to eat them in the evening (12\%) or in the morning (1\%).

Except for subjective norm and social support, mean scores on the personal and social environmental predictors of limiting the consumption of high-fat snacks were positive (Table 1). In particular, the perceived behaviour of the mother and father and self-efficacy were positive, indicating that the students perceived their mother and father to eat few high-fat snacks and that they found it easy to limit their own high-fat snack consumption. Subjective norm and social support were negative, indicating that students perceived that other people do not think they should limit their consumption of high-fat snacks and perceived their environment as not really supportive towards eating fewer high-fat snacks. The mean attitude and intention scores were close to neutral. Fifty-eight per cent of the students reported some parental rules at home about eating high fat-snacks (data not shown). High-fat snacks were perceived to be generally available and accessible at home (mean 9.0, SD 2.8). 
Table 2 Results of stepwise regression analyses with intention to perform a given behaviour as dependent variable and gender, age (step 1), attitude, descriptive norm of the mother, descriptive norm of the father, subjective norm, social support, self-efficacy (step 2)†, food rules, and fruit availability and accessibility (step 3 ) as predictor variables

\begin{tabular}{|c|c|c|c|c|c|c|c|}
\hline \multirow[b]{2}{*}{ Intention } & \multirow[b]{2}{*}{ Predictor } & \multicolumn{2}{|c|}{ Step 1} & \multicolumn{2}{|c|}{ Step 2} & \multicolumn{2}{|c|}{ Step 3} \\
\hline & & $\beta$ weights & $R^{2}$ & $\beta$ weights & $R^{2}$ & $\beta$ weights & $R^{2}$ \\
\hline \multirow[t]{10}{*}{ Increase consumption of fruit $(n=204)$} & Gender & 0.09 & 0.01 & 0.08 & $0.26^{\star \star}$ & 0.06 & $0.27^{* *}$ \\
\hline & Age & -0.02 & & -0.05 & & -0.04 & \\
\hline & Attitude & & & $0.25^{\star \star}$ & & $0.26^{\star \star}$ & \\
\hline & Perceived behaviour of mother & & & $-0.15^{\star}$ & & $-0.14^{*}$ & \\
\hline & Perceived behaviour of father & & & $-0.19^{\star \star}$ & & $-0.18^{\star}$ & \\
\hline & Subjective norm & & & $0.20^{\star}$ & & $0.19^{*}$ & \\
\hline & Social support & & & $0.17^{\star}$ & & $0.19^{*}$ & \\
\hline & Self-efficacy & & & $0.15^{\star *}$ & & $0.16^{*}$ & \\
\hline & Food rules & & & & & 0.05 & \\
\hline & Food availability and accessibility & & & & & -0.10 & \\
\hline \multirow{10}{*}{ Limit consumption of high-fat snacks $(n=194)$} & Gender & $0.24^{\star \star}$ & 0.06 & $0.19^{\star \star}$ & $0.26^{\star \star}$ & $0.20^{\star \star}$ & $0.27^{\star *}$ \\
\hline & Age & 0.04 & & 0.07 & & 0.08 & \\
\hline & Attitude & & & $0.39^{* *}$ & & $0.35^{\star \star}$ & \\
\hline & Perceived behaviour of mother & & & 0.05 & & 0.04 & \\
\hline & Perceived behaviour of father & & & 0.05 & & 0.06 & \\
\hline & Subjective norm & & & $0.19^{\star \star}$ & & $0.17^{*}$ & \\
\hline & Social support & & & -0.01 & & -0.04 & \\
\hline & Self-efficacy & & & -0.12 & & -0.11 & \\
\hline & Food rules & & & & & 0.04 & \\
\hline & Food availability and accessibility & & & & & 0.10 & \\
\hline \multirow{10}{*}{ Have breakfast more frequently $¥(n=163)$} & Gender & 0.10 & 0.01 & 0.14 & $0.20^{\star \star}$ & 0.14 & $0.20^{\star \star}$ \\
\hline & Age & 0.03 & & 0.05 & & 0.02 & \\
\hline & Attitude & & & $0.33^{\star *}$ & & $0.33^{\star *}$ & \\
\hline & Perceived behaviour of mother & & & -0.16 & & -0.15 & \\
\hline & Perceived behaviour of father & & & 0.02 & & 0.02 & \\
\hline & Subjective norm & & & $0.26^{\star}$ & & $0.26^{*}$ & \\
\hline & Social support & & & -0.07 & & -0.07 & \\
\hline & Self-efficacy & & & 0.04 & & 0.04 & \\
\hline & Food rules & & & & & -0.02 & \\
\hline & Food availability and accessibility & & & & & -0.00 & \\
\hline
\end{tabular}

${ }^{\star}, P<0.05 ;{ }^{* *}, P<0.01$.

$\dagger$ See the footnotes of Table 1 for the direction of the potential personal predictors of fruit, snack and breakfast consumption $\ddagger$ Only students who were not always eating a breakfast were selected.

Gender, attitude and subjective norm were significant correlates of intention to limit consumption of high-fat snacks (Table 2). Students who had greater intentions to limit high-fat snack consumption were more likely to be girls, had a more negative attitude towards eating high-fat snacks, and were more likely to think that other people expect them to limit their high-fat snack consumption than students who had less intention. Attitude, perceived behaviour of the mother, and food availability and accessibility were significant correlates of high-fat snack consumption (Table 3). Students who consumed more high-fat snacks had a more negative attitude towards limiting high-fat snack consumption and perceived their mother to eat less high-fat snacks, while they perceived snack availability and accessibility to be higher than students who ate fewer high-fat snacks.

\section{Breakfast}

Two hundred and three students, 52\% male, completed the breakfast questionnaire. Twenty-one per cent were aged 12 years, 40\% were aged 13 years and 39\% were aged 14 years. Most students (70\%) lived with both parents. A large majority of the students had parents whose native country was The Netherlands: $75 \%$ of the mothers and $68 \%$ of the fathers were born in The Netherlands.

Mean breakfast consumption was 4.8 (SD 2.5) days a week. Eight per cent never had breakfast and 50\% reported to eat breakfast every day. Most students who had breakfast indicated that they had it at home (87\%), some reported to eat breakfast at school (9\%), or on the way to school (2\%), or elsewhere (2\%).

Except for social support and intention to have breakfast more frequently in the next 6 months, mean scores on the personal and social environmental predictors of breakfast consumption were positive (Table 1). Especially, the perceived behaviour of the mother and self-efficacy towards having breakfast were positive, indicating that the students perceived their mothers as having breakfast frequently and that they found it easy to have breakfast regularly. Forty-seven per cent of the students reported that there are rules at home about having breakfast (data not shown). Breakfast items were perceived as generally available and accessible at home (mean 5.5, SD 1.6). 
Table 3 Results of stepwise regression analyses with behaviour as dependent variable and gender, age (step 1), attitude, descriptive norm of the mother, descriptive norm of the father, subjective norm, social support, self-efficacy, intention to perform a given behaviour (step 2)†, food rules, and fruit availability and accessibility (step 3) as predictor variables

\begin{tabular}{|c|c|c|c|c|c|c|c|}
\hline \multirow[b]{2}{*}{ Behaviour } & \multirow[b]{2}{*}{ Predictor } & \multicolumn{2}{|c|}{ Step 1} & \multicolumn{2}{|c|}{ Step 2} & \multicolumn{2}{|c|}{ Step 3} \\
\hline & & $\beta$ weights & $R^{2}$ & $\beta$ weights & $R^{2}$ & $\beta$ weights & $R^{2}$ \\
\hline \multirow[t]{11}{*}{ Consumption of fruit $(n=204)$} & Gender & 0.02 & \multirow[t]{11}{*}{0.004} & 0.07 & \multirow[t]{11}{*}{$0.29^{* *}$} & 0.08 & \multirow[t]{11}{*}{$0.30^{\star *}$} \\
\hline & Age & 0.06 & & 0.04 & & 0.04 & \\
\hline & Attitude & & & $0.47^{\star *}$ & & $0.48^{\star *}$ & \\
\hline & Perceived behaviour of mother & & & 0.13 & & 0.13 & \\
\hline & Perceived behaviour of father & & & 0.11 & & 0.10 & \\
\hline & Subjective norm & & & -0.10 & & -0.10 & \\
\hline & Social support & & & 0.06 & & 0.08 & \\
\hline & Self-efficacy & & & 0.07 & & 0.07 & \\
\hline & Intention to change & & & $-0.14^{*}$ & & -0.14 & \\
\hline & Food rules & & & & & -0.05 & \\
\hline & Food availability and accessibility & & & & & 0.00 & \\
\hline \multirow[t]{11}{*}{ Consumption of high-fat snacks $(n=194)$} & Gender & $-0.14^{*}$ & \multirow[t]{11}{*}{0.02} & -0.06 & \multirow[t]{11}{*}{$0.26^{\star \star}$} & -0.08 & \multirow[t]{11}{*}{$0.29^{* \star}$} \\
\hline & Age & 0.06 & & 0.01 & & -0.01 & \\
\hline & Attitude & & & $-0.42^{\star \star}$ & & $-0.36^{\star \star}$ & \\
\hline & Perceived behaviour of mother & & & 0.11 & & $0.13^{\star}$ & \\
\hline & Perceived behaviour of father & & & 0.04 & & 0.03 & \\
\hline & Subjective norm & & & -0.61 & & -0.05 & \\
\hline & Social support & & & 0.02 & & 0.07 & \\
\hline & Self-efficacy & & & -0.05 & & -0.06 & \\
\hline & Intention to change & & & -0.11 & & -0.08 & \\
\hline & Food rules & & & & & -0.07 & \\
\hline & Food availability and accessibility & & & & & $-0.17^{*}$ & \\
\hline \multirow[t]{11}{*}{ Breakfast frequency $(n=203)$} & Gender & $-0.18^{*}$ & \multirow[t]{11}{*}{0.04} & -0.10 & \multirow[t]{11}{*}{$0.27^{\star \star}$} & -0.08 & \multirow[t]{11}{*}{$0.29^{* \star}$} \\
\hline & Age & -0.09 & & -0.08 & & -0.07 & \\
\hline & Attitude & & & $0.31^{\star *}$ & & $0.28^{\star *}$ & \\
\hline & Perceived behaviour of mother & & & 0.06 & & 0.05 & \\
\hline & Perceived behaviour of father & & & 0.11 & & 0.09 & \\
\hline & Subjective norm & & & 0.09 & & 0.07 & \\
\hline & Social support & & & -0.02 & & -0.06 & \\
\hline & Self-efficacy & & & 0.06 & & 0.07 & \\
\hline & Intention to change & & & 0.11 & & 0.11 & \\
\hline & Food rules & & & & & 0.07 & \\
\hline & Food availability and accessibility & & & & & 0.12 & \\
\hline
\end{tabular}

${ }^{*}, P<0.05 ;{ }^{* *}, P<0.01$.

$\dagger$ See the footnotes of Table 1 for the direction of the potential personal predictors of fruit, snack and breakfast consumption.

Attitude and subjective norm were significant correlates of intention to eat breakfast more frequently (Table 2). Students who had a greater intention to have breakfast more frequently had a more positive attitude towards eating breakfast and more strongly thought that other people expect them to eat breakfast than students who had less intention. Attitude was the only significant correlate of breakfast consumption (Table 3). Frequent breakfast-eaters had a more positive attitude towards eating breakfast than those who had breakfast rarely.

\section{Discussion}

In this study, we have investigated the relative importance of personal and social environmental predictors of consumption of fruit, high-fat snacks and breakfast. The results show that mean fruit intake was below recommended levels, although intake of fruit juice was not accounted for. It was quite remarkable that fake fruit beverages such as soft drinks with a fruit taste, lemonade and yoghurts with a fruit taste were often reported as the most frequently consumed fruit juices. This indicates that students have difficulties in distinguishing real fruit juice from non-juice beverages. Once in every three days the students in the present study consumed different categories of high-fat snacks, and half of the students did not have breakfast every day. About a quarter of the variation in actual behaviour and in intention to change the different behaviours could be accounted for by the combination of demographic, psychosocial and social environmental factors that were included in the present study, which corresponds with a large effect size according to the criteria proposed by Cohen $^{25}$. Our analyses showed a number of significant predictors of intention to eat more fruit, to limit snack intake and to have a breakfast more frequently. In particular, attitudes and subjective norms appeared to be relevant predictors of intention of all three dietary behaviours, while selfefficacy appeared to be relevant for fruit intake. For intention to improve fruit intake, social influences seemed to play a more important role than for snack intake and breakfast frequency. Girls had higher intentions to limit 
the consumption of high-fat snacks than boys. Attitude was the only consistent predictor of the three dietary behaviours.

Recent research has shown that low fruit consumption, frequent snacking on high-fat foods and skipping breakfast are common among adolescents ${ }^{1-5}$. The most recent Dutch national food consumption survey showed, for example, that mean fruit intake among 10-16-year-old students was 0.9 pieces per day. Furthermore, $65 \%$ of these students did not eat the 2 pieces of fruit daily that are recommended in The Netherlands ${ }^{2}$. Likewise, Schaalma et al. found that 12-14-year-old students ate 1.1 pieces of fruit per day ${ }^{1}$. These findings are in line with the results in the present study. For our findings on snack intake and breakfast frequency, no comparable Dutch data among a similar age group are available. In this study it was quite unique to have close to a $100 \%$ response rate to the questionnaire. However the teacher chose the classes for the study, which may have had implications for the results. Teachers may have selected classes with a high interest for nutrition education. However, observations and discussions with the teacher do not indicate this potential selection bias.

The amount of variance explained is in line with previous research, where on average no more than $30 \%$ of the variance in nutrition behaviour could be explained ${ }^{26}$. Although we included potential determinants additional to the ASE determinants, like food rules and food availability and accessibility, this did not result in higher explained variance. Family food rules were identified as relevant predictors of adolescents' eating behaviours in a study conducted in Belgium ${ }^{21}$. However, in the present study, family food rules seemed unimportant predictors for eating fruits and having breakfast, but this might be due to low validity of the measure. Nevertheless, more research is needed on other factors that could enhance the explanatory variance of consuming fruits, snacks and breakfasts. Earlier research has argued that behaviour performed repeatedly over a long period of time, like nutrition behaviour, becomes habitual. If students experience nutrition behaviour as a habit they may become less aware of the reasons for performing the behaviour. Nutrition behaviour is not only dependent on personal factors, but also environmental factors may be important. Recently conducted research found that general parenting style may be a relevant environmental predictor of adolescents' fruit and vegetable behaviour $^{27,28}$.

Attitude was found to be the most important predictor of behavioural intentions. This could be due to the fact that attitude was measured in more detail than the other determinants. However, our results are in line with previous research, in which attitude was also found to be an important factor influencing food choice decisions ${ }^{29}$. Secondary analysis found that especially the following beliefs contributed to differences in intentions to increase consumption of fruit (where + indicates a positive association, - indicates a negative association): if I eat fruit I feel good (+), eating fruit makes me eat less snacks $(+)$, eating fruit is good $(+)$, eating fruit is only necessary when feeling sick $(-)$, if you are young eating fruit is not necessary (-). For limiting snacks, the following beliefs contributed: eating snacks is sociable $(-)$, eating snacks is bad for dieting $(+)$, if I feel bad-tempered I have to eat snacks $(-)$, if I eat snacks I feel guilty $(+)$. On the other hand, the following beliefs contributed more often towards increasing breakfast frequency: eating a breakfast is good (+), eating a breakfast is suitable for persons like me (+). Targeting these beliefs in interventions to promote healthy diets may strengthen attitudes towards healthy dietary habits and improve intentions to change. Besides attitude, subjective norm was an important predictor of behavioural intentions. Greater weightconsciousness among girls might explain their higher intention to limit snack intake. For fruit intake different social influences as well as self-efficacy seemed to be more important than for the other two behaviours. Because fruit intake has already been targeted in nutrition education interventions in recent years, it may be that students are more aware of the norms promoting fruit intake, as well as potential barriers towards eating more fruit.

Attitude was also the main predictor of actual behaviour. In addition, for snack consumption, mothers' behaviour as well as perceived availability of relevant foods may be relevant predictors of students' intake levels. However, students' snack intake was inversely related to the perceived intake of their mother. Students who more frequently eat high-fat snacks may perceive their mothers' consumption to be low compared with their own consumption levels. A more relevant finding may be the positive association between availability and accessibility of high-fat snacks and eating high-fat snacks, indicating that restricting availability may help to limit snack intake.

In this study we studied possible predictors of both intention to change and actual behaviour. The correlates (potential determinants) of intake may help to explain present behaviour, which provides more insight into why adolescents eat what they eat. However, for promotion of more healthful diets, dietary change may be required, and in order to detect relevant variables that should be targeted in such interventions, insight into correlates of the intention to change is more relevant.

The results presented here imply that interventions to increase fruit and fruit juice consumption, decrease consumption of high-fat snacks and increase breakfast consumption should at least include methods and strategies aimed at achieving positive attitudes towards these behaviours. Attitude change is most often aimed at by means of persuasive communication, i.e. nutrition education leaflets, brochures, etc., that communicate arguments for dietary behaviour change. However, since the results indicate that dietary behaviour may not be 
a strongly reasoned action in this age group, healthy dietpromoting interventions are advised to look for more creative and alternative ways to achieve adolescents' having positive associations with healthy dietary changes. Mere exposure is an example of such an alternative. Mere exposure implies that students should be frequently exposed to fruits, low-fat snacks and breakfast items ${ }^{30}$. Strategies based on mere exposure, such as preparing foods, taste-testing lessons and exposure to low-fat snacks, may encourage students to eat more fruits, eat a low-fat snack instead of a high-fat snack and have breakfast more frequently. Other creative ways that may enhance students to make positive changes towards dietary changes are puzzles, tests and a comic. It is recommended to consider these findings in the development of new nutrition education programmes.

\section{References}

1 Schaalma H, Bolman C, de Nooijer J, de Vries H, Paulussen T, Aarts $\mathrm{T}$, et al. Jongeren en de preventie van hart-en vaatziekten. Een leefstijl- en determinantenanalyse [Adolescents and the Prevention of Cardiovascular Disease]. Den Haag: Nederlandse Hartstichting, 1997.

2 Voedingscentrum. Zo eet Nederland, Resultaten van de Voedselconsumptiepeiling 1997-1998 [The Results of the Dutch National Food Consumption Survey 1997-1998]. Den Haag: Voedingscentrum, 1998

3 Department of Health. The NHS Plan: A Plan for Investment, A Plan for Reform. London: HMSO, 2000.

4 Health Education Authority (HEA). Young People and Health: Health Behaviour in School Aged Children. A Report of the 1997 Findings. London: HEA, 1999.

5 Munoz KA, Krebs-Smith SM, Ballard-Barbasch R, Cleveland LE. Food intake of US children and adolescents compared with recommendations. Pediatrics 1997; 100: 323-9.

6 Matthews R. Importance of breakfast to cognitive performance and health. Perspectives on Applied Nutrition 1996; 3: 204-12.

7 Pollit E. Does breakfast make a difference in school? Journal of the American Dietetic Association 1995; 95: 1134-9.

8 Pollit E. Breakfast and cognition: an integrative summary. American Journal of Clinical Nutrition 1998; 67: 804S-13S.

9 Willett WC. Diet and health: what should we eat? Science 1994; 264: 532-7.

10 Gezondheidsraad. Overgewicht en obesitas (a report on overweight and obesity of the Health Council of the Netherlands). Den Haag: Gezondheidsraad, 2003.

11 Hirasing RA, Fredriks AM, Van Buren S, Verloove-Vanhorick SP, Wit JM. Toegenomen prevalentie van overgewicht en obesitas bij Nederlandse kinderen en signalering daarvan aan de hand van internationale normen en nieuwe referentiediagrammen [Increased prevalence of overweight and obesity among Dutch children and pointing this out using international norms and new reference diagrams]. Nederlands Tijdschrift voor Geneeskunde 2001; 145: 1303-8.

12 World Health Organization (WHO). Life in the 21st Century - A Vision for All. The World Health Report. Geneva: WHO, 1998.
13 Krebs-Smith SM, Heimendinger J, Patterson BH, Subar AF, Kessler R, Pivonka E. Psychosocial factors associated with fruit and vegetable consumption. American Journal of Health Promotion 1995; 10: 89-104.

14 Branen L, Fletcher J. Comparison of college students' current eating habits and recollections of their childhood food practices. Journal of Nutrition Education 1999; 31: 304-10.

15 Lytle LA, Seifert S, Greenstein J, McGovern P. How do children's eating patterns and food choices change over time? Results from a cohort study. American Journal of Health Promotion 2000; 14: 222-8.

16 de Vries M, da Costa Senior R. Scholieren en tussendoortjes: onderzoek naar eet- en drinkgewoonten tijdens schooltijd van leerlingen in het basis- en voortgezet onderwijs in Midden-Holland [Research into Eating and Drinking Habits during School Hours among Students of Secondary Schools and High Schools]. Gouda: GGD Midden Holland, 1992.

17 Koivisto Hursti UK. Factors influencing children's food choice. Annals of Behavioral Medicine 1999; 31: 26-32.

18 Roos E, Lahelma E, Virtanen M, Prättälä R, Pietinen P. Gender, socioeconomic status and family status as determinants of food behaviour. Social Science \& Medicine 1998; 46 : 1519-29.

19 Green LW, Kreuter MW. Health Promotion Planning: An Educational and Ecological Approach, 3rd ed. Mountain View, CA: Mayfield, 1999.

20 de Vries H, Dijkstra M, Kuhlman P. Self-efficacy: the third factor besides attitude and subjective norm as a predictor of behavioural intentions. Health Education Research 1988; 3: $273-82$.

21 de Bourdeaudhuij I. Family food rules and healthy eating in adolescents. Journal of Health Psychology 1997; 2: 45-56.

22 Baranowski T, Davis M, Resnicow K, Baranowski J, Doyle C, Lin L, et al. Gimme 5 fruit, juice, and vegetables for fun and health: outcome evaluation. Health Education \& Behavior 2000; 27: 96-111.

23 van Assema P, Brug J, Ronda G, Steenhuis I, Oenema A. A short Dutch questionnaire to measure fruit and vegetable intake: relative validity among adults and adolescents. Nutrition and Health 2002; 16: 85-106.

24 van Assema P, Brug J, Ronda G, Steenhuis IMH. The relative validity of a short Dutch questionnaire as a means to rank adults to total and saturated fat intake. Journal of Human Nutrition and Dietetics 2001; 14: 377-90.

25 Cohen J. Statistical Power Analysis for Behavioural Sciences. Hillsdale, New York: Erlbaum, 1988.

26 Baranowski T, Cullen KW, Baranowski J. Psychosocial correlates of dietary intake: advancing dietary intervention. Annual Review of Nutrition 1999; 19: 17-40.

27 Kremers SPJ, Brug J, de Vries H, Engels RCME. Parenting style and adolescent fruit consumption. Appetite 2003; 41: $43-50$.

28 Lytle LA, Varnell S, Murray DM, Story M, Perry C, Birnbaum AS, et al. Predicting adolescents' intake of fruit and vegetables. Journal of Nutrition Education and Behavior 2003; 35: 170-5.

29 Dennison CM, Shepherd R. Adolescent food choice: an application of the theory of planned behaviour. Journal of Human Nutrition and Dietetics 1995; 8: 9-23.

30 Zajonc RB. Attitudinal effects of mere exposure. Journal of Personality and Social Psychology 1968; 9: 1-27. 